\title{
The impact of SARS-CoV-2 on the accessibility of multidisciplinary diagnostics of neurodevelopmental disorders in Flanders, Belgium
}

Eva Cloet ( $\nabla$ eva.cloet@vub.be )

Vrije Universiteit Brussel

\author{
Anna Jansen \\ Vrije Universiteit Brussel \\ Mark Leys \\ Vrije Universiteit Brussel
}

\section{Research Article}

Keywords: Developmental disorders, Diagnostic assessment, Children, SARS-CoV-2, COVID, healthcare organization, accessibility, interorganisational collaboration

Posted Date: December 9th, 2020

DOI: https://doi.org/10.21203/rs.3.rs-111002/v1

License: (우 (i) This work is licensed under a Creative Commons Attribution 4.0 International License. Read Full License 


\section{Abstract}

Background Neurodevelopmental disorders start in early childhood and may restrict personal, scholastic, social and professional development and functioning. Early detection and smooth trajectories of diagnostics, rehabilitation and support affect the child's development and opportunities. A specialized multidisciplinary team must do a diagnostic evaluation. While accessibility to multidisciplinary diagnostics for all children in Flanders (Belgium) is problematic in regular times, the lockdown measures taken by the end of March 2020 in response to the SARS-CoV-2 pandemic could amplify this problem. This article aims to explore the impact of lockdown policy measures on the accessibility of multidisciplinary diagnostics of developmental disorders.

Methods This "rapid response" study was commissioned by the Flemish authorities, as a follow up of a broader study on accessibility of multidisciplinary diagnostics. A questionnaire with open-ended questions was sent out to respondents of three key types of facilities: the Centers for Ambulatory Rehabilitation, Autism Reference Centers and Centers for Developmental Disorders. Qualitative data were thematically analyzed in an iterative process by researcher triangulation.

Results Measures taken in response to the SARS-CoV-2 pandemic negatively impacted on waiting periods which lengthened with at least three months and even longer for certain target groups. Specific guidelines to minimize the risk of virus contamination, impact on planning, time management and the quality of the diagnostic assessments. Respondents reported them as being time consuming, uncomfortable, with an increasing workload and leading to a reduction in the number of daily diagnostic activities. Suggested catchingup strategies were increase of public funding, a less rigid application of regulations and a complete or partial assignment stop.

Conclusion The SARS-CoV-2 pandemic reinforced the existing problem of accessibility because of a general shortage of diagnostic capacity. On a shorter term accessibility problems can be tempered by providing "bridging care" during waiting periods. On the longer term, strengthening regional interorganisational collaboration is required, to enhance more efficient and effective diagnostic trajectories in facilities providing adapted services to the needs of the children.

\section{Background}

Neurobiological developmental delays and disorders start in early childhood and may restrict personal, scholastic, social and professional development and functioning (American Psychiatric Association, 2014). Early detection and smooth trajectories of diagnostics, rehabilitation and support influence the child's development and opportunities later in life. Considering the complexity and dynamic character of developmental disorders, multidisciplinary diagnostic evaluations are needed in different stages of the developmental trajectory, assessing all areas of development (verbal and non-verbal cognition, expressive and receptive language, fine and gross motor development, social communication, social-emotional development) by a multidisciplinary team (Petersen, Kube, \& Palmer, 1998). Moreover, early detection and well organized care trajectories potentially decrease service utilization and economic burden later in life (e.g. prevent academic failure, behavior problems, dropout, delinquency and the development of more severe mental health issues in later life) (Majnemer, 1998; Ozonoff, 2015). The available evidence offers clear arguments to enhance (early) access to multidisciplinary diagnostics (MD) while practice shows that getting timely and adequate access is challenging. Known factors affecting access to health care are the availability of services (for all ages and pathologies), availability of necessary technologies, availability of required competences, geographical access and regional disparities, financial access and affordability, acceptability of care (patient satisfaction with health services provided), adequacy of accommodation (infrastructure, procedure for planning and appointments), and awareness (communication and information about the care provided with the target group and stakeholders) (Israel, 2016; Penchansky \& Thomas, 1981; Saurman, 2016).

The challenge of adequate access to MD for people with suspected developmental disorders is on the agenda in Flanders, Belgium. Flanders has a population of 6, 596 million inhabitants. $19 \%$ of this population is younger than 18 years. Access to MD in Flanders is problematic. There is limited availability of diagnostic services for specific target and age groups and waiting periods amount to over a year. Self-reported mean waiting periods are up to 90 weeks (Cloet, Kimpe, Van Ransbeeck, \& Leys, 2020). Moreover, the field of services for MD of developmental disorders in Flanders is heterogeneous. About 160 publicly recognized and financed centers offer multidisciplinary assessments for children and adolescents, but these are geographically unevenly distributed and have great variability in capacity. Organizations differ in activities and objectives and work within different regulative frameworks. Some organizations are specialized in diagnostics of developmental disorders as main activity (Centers for Ambulatory Rehabilitation (CAR), Centers for Developmental Disorders (CDD) and Autism Reference Centers (ARC), while others perform diagnostics in the context of other activities e.g. rehabilitation or support for children or youth (Mental Healthcare Centers (MHC), Centers for Pupil Guidance (CPG) and the Ambulatory Services for Paediatric Neuropsychiatry (APP)). Work practices differ between organizations. They are influenced by 
organizational goals, target groups, habits, regulations and financing, composition of the multidisciplinary team, and vision on the diagnostic process and assessment. From a health services perspective there is no policy coordination mechanism addressing the question what type of organization provides what type of diagnostics for what group under what circumstances (Cloet et al., 2020).

Reported access barriers for diagnostics of developmental disorders in Flanders are availability, accessibility for vulnerable groups, affordability, adequacy of accommodation and awareness. One key access barrier, as a component of availability, are the waiting periods. Two types of waiting periods can be identified: the waiting period between the first contact and the anamnestic interview at the start of the assessment, and the waiting period between the anamnestic interview and the first examination or observation in the overall assessment. Waiting times differ between different types of organizations, but also between organizations of the same type. Waiting periods vary depending on the age of the child (most organizations give priority to children younger than 6 years old), the suspected disorder (more diagnostic trajectories for ADHD and autism spectrum disorder, less for specific learning disorders), the type of organization (more trajectories in the CDD, only few in MHC) and the region (almost no diagnostic trajectories reported in Limburg and West-Flanders). This problematic accessibility of diagnostics leads to a loss of precious time, increasing primary and secondary symptoms of developmental disorders and undermining continuity of care. (Cloet et al., 2020).

A potential complicating factor of accessibility are the measures taken in response to the SARS-CoV-2 pandemic. By the end of March 2020, Belgium went in a state of lockdown with invasive physical distancing measures and movement restrictions. Services, schools and shops, with exception of those selling essential supplies, were closed. People were very limited to leave their home. Measures lasted from March until the end of May 2020. The COVID-19 measures evolved from a total lockdown in the first phase to a gradual reactivation by the end of May with the obligatory use of personal protection material in a second phase.

This article aims to explore the impact of lockdown policy measures taken in response to the SARS-CoV-2 pandemic on the accessibility of MD of developmental disorders.

\section{Methods}

This is a "rapid response" study commissioned by the Flemish authorities, as a follow up of a broader study on accessibility of MD. The rapid response study was performed in a period of 6 weeks. However, much knowledge on problems of accessibility and the organization of MD was already acquired in the preceding study (Cloet et al., 2020).

\section{Data-collection}

In order to explore the impact of SARS-CoV-2 policy measures on the accessibility of diagnostics of developmental disorders, a questionnaire with open-ended questions was sent out in June 2020 to respondents of three key types of facilities: the Centers for Ambulatory Rehabilitation, the Autism Reference Centers and the Centers for Developmental Disorders. The questionnaire was e-mailed to the directors of the CDD, the directors/coordinators of the CAR and the leading psychiatrists of the ARC. Participants had 8 days to response.

The questionnaire probed the respondents with open ended questions on the perceived impact of the SARS-CoV-2 policy measures on the accessibility of MD in their organization, with particular attention to the evolution of waiting lists and waiting periods, changes in working processes and action strategies at the restart after the lockdown period. The development of the questionnaire was based on the reported problematic accessibility and waiting lists in previous research (Cloet et al., 2020) and with the intention to collect as much information as possible on the impact of the SARS-CoV-2 measures and organizational strategies.

\section{Data-analysis}

Qualitative Data were analyzed using thematic analysis (Belotto, 2018; Maguire \& Delahunt, 2017). We distinguished two general phases: the lockdown phase and the reactivation phase with personal protection measures. Furthermore, we clustered the answers on the perceived impact of the measures on clients and their families.

EC (PhD-researcher and director of a center for developmental disorders) and ML (sociologist and head of the research group Organisation, Policy and Social Inequalities in Healthcare at Vrije Universiteit Brussel), experienced researchers in healthcare organization themes, analyzed the data in an iterative process by researcher triangulation (Abdalla, Oliveira, Azevedo, \& Gonzalez, 2017; Jonsen \& Jehn, n.d.). This qualitative research method was also applied by the researchers in the multi-method study on the same 
theme, prior to this study (Cloet et al., 2020). Data analysis of the current study is built on the knowledge gained previously and insights form both studies were triangulated.

\section{Ethics approval and consent to participate}

It concerns a research project addressing questions regarding organizational issues and strategies without any reference to personal data. No personal health data were collected or subject to the analysis All methods were carried out in accordance with relevant guidelines and regulations for qualitative data-analysis and reporting. As there were no experiments involved, approvement by an institutional and/or licensing committee was not applicable.

Participants were free to answer the questionnaire or not to participate. The introduction of the questionnaire clearly mentioned the purpose of the project, being a rapid response study commissioned by the Flemish authorities. Seen the design and methods of the study, an individual informed consent from all subjects was not of relevance.

\section{Results}

\section{Response}

The response rate was 0.60 . Table 1 summarizes the response by type of center and by geographical subregion of Flanders where the centers are located. All 4 centers for developmental disorders, 3 of 4 autism reference centers and 23 of 42 centers for ambulatory rehabilitation responded. The lower response of the CAR can be explained by the fact that some CARs focus on rehabilitation while collaborating with other organizations (e.g. CDD) for diagnostics (so diagnostics is not their core internal activity).

The response mirrors the geographical distribution of the centers per subregion in Flanders. 
Table 1

Response by type of organization and by subregion

\begin{tabular}{|c|c|c|c|c|}
\hline Region & $\begin{array}{l}\text { Included centers per } \\
\text { type of organization }\end{array}$ & $\begin{array}{l}\text { Response per type } \\
\text { of organization }\end{array}$ & Total number of centers included & $\begin{array}{l}\text { Total } \\
\text { response }\end{array}$ \\
\hline \multirow[t]{3}{*}{ Antwerp } & CDD: 1 & CDD: 1 & 6 & 4 \\
\hline & ACR: 1 & ACR: 1 & & \\
\hline & CAR: 4 & CAR: 2 & & \\
\hline \multirow[t]{3}{*}{ Brussels Capital Region and periphery } & CDD: 1 & CDD: 1 & 5 & 3 \\
\hline & ACR: 1 & ACR: 1 & & \\
\hline & CAR: 3 & CAR: 1 & & \\
\hline \multirow[t]{3}{*}{ Limburg } & CDD: 0 & CDD: 0 & 2 & 1 \\
\hline & ACR: 0 & ACR: 0 & & \\
\hline & CAR: 2 & CAR: 1 & & \\
\hline \multirow[t]{3}{*}{ East-Flanders } & CDD: 1 & CDD: 1 & 20 & 14 \\
\hline & ACR: 1 & ACR: 1 & & \\
\hline & CAR: 18 & CAR: 12 & & \\
\hline \multirow[t]{3}{*}{ Flemish Brabant } & CDD: 1 & CDD: 1 & 6 & 3 \\
\hline & ACR: 1 & ACR: 0 & & \\
\hline & CAR: 4 & CAR: 2 & & \\
\hline \multirow[t]{3}{*}{ West -Flanders } & CDD: 0 & CDD: 0 & 11 & 5 \\
\hline & ACR: 0 & ACR: 0 & & \\
\hline & CAR: 11 & CAR: 5 & & \\
\hline \multirow[t]{3}{*}{ Flanders (total) } & $C D D: 4$ & $C D D: 4$ & 50 & 30 \\
\hline & ACR: 4 & ACR: 3 & & \\
\hline & CAR: 42 & CAR: 23 & & \\
\hline
\end{tabular}

\section{Impact of SARS-CoV-2 measures on the organization and working processes}

All centers reported an impact of the policy measures on working processes. The most pervading measures were the cessation of diagnostic activities, which were eventually replaced by teleconsultations for a limited range of activities. In the second phase, working practices (and contacts with clients) required the use of personal protection material (mouth masks, face shields, gloves and respecting a safe distance of 1,5 meter). For the material used during the diagnostic process (test batteries, toys), specific guidelines have been developed to minimize the risk of contamination. Test material had to be replaced by washable material and needed to be disinfected between consultations. Face shields and plexiglass screens were used when the required social distancing measures could not be respected. These changes had an impact on the workload, planning and time management and potentially on the quality of the diagnostic assessments (Table 2-4). Respondents reported them as being very time consuming, uncomfortable and with an increasing impact on workload and leading to a reduction in the number of daily diagnostic activities.

\section{Impact of SARS-CoV-2 measures during the lockdown phase}

During the total lockdown, face-to-face diagnostic activity was suspended in all organizations. The CAR reported a continuation of sending and processing of diagnostic questionnaires, as part of the diagnostic assessments. CDD reported a shift towards teleconsultations with a selection of patients/families in ongoing diagnostic trajectories. Children on the waiting list were prioritized by a 
collaborator, assessing the urgency level of the diagnostic assessment but not always based on standardized criteria. In one CDD, a complete assignment stop was introduced during the 3 months of the total lockdown.

Consultations by phone or teleconference were initiated in all organizations, but were experienced as suboptimal and unable to substitute necessary activities in the diagnostic trajectory. CAR reported that high-quality diagnostics could not be offered during this lockdown period.

Table 2

Impact of SARS-CoV-2 measures on the working processes during the inactive phase of total lockdown

\begin{tabular}{|c|c|c|c|}
\hline & CDD & CAR & ARC \\
\hline Accessibility & $\begin{array}{l}\text { One CDD closed the assignment procedure during } \\
3 \text { months because of the increasing waiting list, } \\
\text { resulting in waiting periods over } 1 \text { year. } \\
\text { Suspension of the diagnostic activity during the } \\
\text { lockdown. }\end{array}$ & $\begin{array}{l}\text { Continuation of } \\
\text { assignments by phone. } \\
\text { Suspension of the } \\
\text { diagnostic activity during } \\
\text { the lockdown period. } \\
\text { Ongoing diagnostic } \\
\text { processes were put on } \\
\text { hold. } \\
\text { Continuation of mailing } \\
\text { and processing diagnostic } \\
\text { questionnaires to parents, } \\
\text { teachers and peers. }\end{array}$ & $\begin{array}{l}\text { Total suspension of the } \\
\text { activity from March until } \\
\text { May, } 2020 .\end{array}$ \\
\hline $\begin{array}{l}\text { Selection } \\
\text { and priority }\end{array}$ & $\begin{array}{l}\text { Ongoing trajectories: selection of children/families with } \\
\text { whom an intermediate contact was needed on behalf of } \\
\text { support. New trajectories: selection and prioritization by } \\
\text { urgency, based on the opinion of a collaborator. }\end{array}$ & & \\
\hline $\begin{array}{l}\text { Care and } \\
\text { support } \\
\text { from a } \\
\text { distance }\end{array}$ & $\begin{array}{l}\text { Teleconsultations (by phone or conference call) were } \\
\text { initiated for anamnestic interviews and discussion of } \\
\text { the outcomes and conclusions of diagnostic } \\
\text { assessments. } \\
\text { Follow-up of families in crises by phone. }\end{array}$ & $\begin{array}{l}\text { Teleconsultations (by } \\
\text { phone or conference call) } \\
\text { were initiated if possible, } \\
\text { but were experienced as } \\
\text { suboptimal. }\end{array}$ & $\begin{array}{l}\text { Teleconsultations (by } \\
\text { phone or conference call) } \\
\text { were initiated, but only for } \\
\text { coordination of care and } \\
\text { support. }\end{array}$ \\
\hline Quality & & $\begin{array}{l}\text { Qualitative diagnostics } \\
\text { could not be offered during } \\
\text { the lockdown period. }\end{array}$ & \\
\hline
\end{tabular}

Table 3 summarizes the impact of the SARS-CoV-2 measures after the period of full lock down. 
Table 3

Impact of SARS-CoV-2 measures on the working processes after the period of full lockdown

\begin{tabular}{|c|c|c|c|}
\hline & CDD & CAR & ARC \\
\hline $\begin{array}{l}\text { Reduction } \\
\text { of capacity } \\
\text { and } \\
\text { consequent } \\
\text { effects }\end{array}$ & $\begin{array}{l}\text { Gradual reactivation, but with } \\
\text { a lower activity grade. This } \\
\text { resulted in effects on } \\
\text { capacity and waiting periods } \\
\text { beyond the period of the } \\
\text { lockdown. } \\
\text { Social distancing measures } \\
\text { limited the allowed number } \\
\text { of patients in the waiting } \\
\text { rooms and affected the } \\
\text { capacity of consultations. }\end{array}$ & $\begin{array}{l}\text { Extra assessments were } \\
\text { planned during the summer } \\
\text { holidays, but this did not } \\
\text { compensate for the } \\
\text { increased waiting lists. }\end{array}$ & $\begin{array}{l}\text { Measures for personal protection (triage of patients, } \\
\text { disinfection of materials, chairs and tables, } \\
\text { limitation of the number of patients in the waiting } \\
\text { rooms) resulted in underutilization of capacity. }\end{array}$ \\
\hline $\begin{array}{l}\text { Patient } \\
\text { selection }\end{array}$ & $\begin{array}{l}\text { Patient with higher health } \\
\text { risks were not allowed to } \\
\text { come to consultations in this } \\
\text { reactivation phase. }\end{array}$ & $\begin{array}{l}\text { Priority was given to } \\
\text { ongoing trajectories, only in } \\
\text { a second phase new } \\
\text { trajectories could start up. } \\
\text { New diagnostic trajectories } \\
\text { were postponed. } \\
\text { Because of the Sars-CoV-2 } \\
\text { measures, there was a delay } \\
\text { and more dispersion of the } \\
\text { diagnostic assessment. }\end{array}$ & \\
\hline Workload & $\begin{array}{l}\text { Measures for personal } \\
\text { protection (disinfection of } \\
\text { materials, chairs and tables, } \\
\text { face shields, and plexiglass } \\
\text { screens between all } \\
\text { consultations) was very time- } \\
\text { consuming. }\end{array}$ & $\begin{array}{l}\text { Measures for personal } \\
\text { protection (disinfection of } \\
\text { materials, face shields, } \\
\text { Plexiglas screen, chairs and } \\
\text { tables between all } \\
\text { consultations) is very time- } \\
\text { consuming. }\end{array}$ & \\
\hline $\begin{array}{l}\text { Quality of } \\
\text { the } \\
\text { diagnostics }\end{array}$ & $\begin{array}{l}\text { Diagnostics of Autism } \\
\text { Spectrum Disorders (ASD): } \\
\text { because of the obliged use of } \\
\text { personal protection material } \\
\text { and social distancing, the } \\
\text { standardization of the main } \\
\text { observation battery (ADOS } 1 \\
\& 2 \text { ) was no longer valid. } \\
\text { Observations based on the } \\
\text { ADOS were replaced by } \\
\text { observation of the child's } \\
\text { playing and interaction } \\
\text { behavior. This hampered the } \\
\text { diagnostic assessment of } \\
\text { ASD. }\end{array}$ & $\begin{array}{l}\text { The use of personal } \\
\text { protection material and } \\
\text { social distancing had an } \\
\text { impact on the behavior and } \\
\text { functioning of the child } \\
\text { (diagnostics of ASD, ADHD) } \\
\text { and on the evaluation of a } \\
\text { child with standardized test } \\
\text { batteries. } \\
\text { School observations could } \\
\text { not always be done when } \\
\text { required for the quality of the } \\
\text { diagnostics, because of the } \\
\text { safety precautions of the } \\
\text { schools. } \\
\text { Social distancing and } \\
\text { personal protection material } \\
\text { hampered the diagnostic } \\
\text { evaluations by } \\
\text { physiotherapists. }\end{array}$ & $\begin{array}{l}\text { Diagnostics of Autism Spectrum Disorders: the } \\
\text { obliged implementation of personal protection } \\
\text { measures hampered the qualitative diagnostics of } \\
\text { ASD. Not only in the use of standardized testing } \\
\text { material, but also because of the unpredictable } \\
\text { behavior of this specific target group in response to } \\
\text { the protection material and their difficulties to } \\
\text { respect the safety precautions. }\end{array}$ \\
\hline
\end{tabular}

In the post-lockdown-phase, respondents reported a reduction of diagnostic capacity because of infrastructural reasons: e.g. reduced numbers of patients in the waiting rooms because of the distancing of 1,5 meters.

CAR reported to work on a catch-up movement of diagnostic trajectories during the summer holidays, in the full awareness that this would not fully compensate the lost capacity during the lockdown and post-lockdown phases.

Organizations also reported "patient selection" using self-defined priority criteria. In the post lock-down phase, CDD excluded patients with a higher health risk (e.g. extreme premature born babies), CAR gave priority to children in an ongoing rehabilitation or diagnostic trajectory. 
All centers reported an impact on the quality of the diagnostic assessments, particularly for the diagnostics of autism spectrum disorders. The use of personal protection material (mouth mask, face shields, plexiglass screens, social distancing measures) hampered the use of standardized test batteries and had an effect on the unpredictable behavior of this specific target group. Protection measures were also difficult to be respected by children with suspected ASD. CAR additionally reported limitations concerning school observations needed for qualitative diagnostics of ASD and ADHD and the impact of protection measures on evaluations by physiotherapists, because of the physical contact they have with very young children.

\section{Impact of SARS-CoV-2 measures on the children and their family}

The SARS-CoV-2 pandemic measures also impacted on the children with a suspected developmental disorder and their families (Table 4). CDD and ARC reported that several families entered into a crisis situation because of the lockdown. Details on the types of crisis were not given. In order to optimally support those families, assistance was given by phone. CDD were confronted with cancellations of appointments during the reactivation phase, caused by the anxiety of contamination. CAR reported drop out of patients who were less motivated to engage in the diagnostic or rehabilitation process. As a CAR provides both diagnostic and rehabilitation trajectories, they reported a delay in onset of rehabilitation trajectories and a prolongation of the overall trajectory in the CAR, resulting in extended waiting periods for newly starting children.

Table 4

Impact of SARS-CoV-2 measures on the children and their family

\begin{tabular}{|c|c|c|c|}
\hline & CDD & CAR & ARC \\
\hline Crisis & $\begin{array}{l}\text { Several families in an ongoing } \\
\text { trajectory came into a crisis } \\
\text { situation because of the } \\
\text { lockdown. To support them as } \\
\text { good as possible, assistance } \\
\text { was given by phone. }\end{array}$ & & $\begin{array}{l}\text { Several families in an ongoing } \\
\text { trajectory came into a crisis } \\
\text { because of the lockdown } \\
\text { situation. To support them as } \\
\text { good as possible, assistance } \\
\text { was given by phone. }\end{array}$ \\
\hline $\begin{array}{l}\text { Canceled } \\
\text { appointments }\end{array}$ & $\begin{array}{l}\text { Many consultations were } \\
\text { canceled because of parental } \\
\text { anxiety. }\end{array}$ & $\begin{array}{l}\text { There was a drop-out of patients/parents } \\
\text { who were less motivated. }\end{array}$ & \\
\hline $\begin{array}{l}\text { Delay/extension } \\
\text { of the trajectory }\end{array}$ & & $\begin{array}{l}\text { Suspension of the diagnostic trajectories } \\
\text { caused delay in the onset of rehabilitation } \\
\text { and extension of the total trajectory in a } \\
\text { CAR. Ongoing trajectories were extended } \\
\text { because of the interruption by the } \\
\text { lockdown period. }\end{array}$ & \\
\hline
\end{tabular}

\section{Impact of SARS-CoV-2 on the total capacity of diagnostic trajectories}

All organizations, except 1 CAR, reported that they performed less diagnostic trajectories in the first semester of 2020 compared to the period between January and June 2019 because of the SARS-CoV-2 measures. All types of centers reported that they did not expect to realize the "target" numbers of diagnostic trajectories predetermined by the government for 2020 , as they would not be able to catch-up without additional measures.

\section{Impact of SARS-CoV-2 on the waiting periods for diagnostics}

Participants of all organizations reported a prolongation of the waiting period at least for the period of the lockdown (3 months). Some organizations introduced anamnestic interviews by teleconsultation (online or by phone), so the waiting period between assignment and anamnestic interview did not increase. However, this did not resolve the problem of the longer waiting periods between anamnestic interview and first examination.

After the lockdown period, efforts focused on 'catching up' the most urgent needs and demands. Centers reported to give priority to young children (0-6y) for new intakes. As a consequence, waiting periods for school-aged children increased more than waiting periods for preschool-aged children (up to a mean of 6 months vs 3 months, on top of the pre-COVID waiting period).

\section{Catch up strategies to compensate the diagnostic delay caused by SARS- CoV-2}

The SARS-CoV-2 measures reinforced the preexisting problems of accessibility of MD. Participants were asked for suggestions on how to tackle the impact of lock down measures. (Table 5) 
Table 5

Suggestions for increased accessibility to MD of developmental disorders for children

\begin{tabular}{|c|c|c|c|}
\hline Strategy & CDD & CAR & ARC \\
\hline Increased diagnostic capacity funded by the Government & - & • & • \\
\hline Increased funding by the Government to expand the diagnostic team & $\cdot$ & $\cdot$ & $\cdot$ \\
\hline Temporary full or partial (certain age groups) assignment stop & - & & - \\
\hline Planning more diagnostic assessments during the summer holidays & & $\cdot$ & \\
\hline $\begin{array}{l}\text { More flexibility of regulations in order to } \\
\text { - decrease the administrative workload and increase the diagnostic capacity } \\
\text { - spread the diagnostic trajectory over more than } 3 \text { months } \\
\text { - make it possible for children come to the CAR during day time (school hours) }\end{array}$ & & • & \\
\hline
\end{tabular}

The main strategy suggested by the CDD, CAR and ARC was to temporarily increase the public financing in order to expand the diagnostic team and the diagnostic capacity. The CAR pleaded for additional temporal resources to catch up during summer holidays and suggest a less rigid use of regulations in order to catch up suspended activities. CDD and ARC suggest a complete or partial assignment stop until all delayed trajectories were catched up.

\section{Discussion}

Flanders is since a longer time confronted with accessibility problems to MD of neurodevelopmental disorders. This article summarized the findings of a rapid response exploration of the impact of the SARS-CoV-2 lock-down measures on this problem .

\section{Growing accessibility problems}

Since long, the field of MD criticizes the lack of capacity (financial as well as human and infrastructural resources) in order to address waiting lists and waiting times and to engage in sufficient diagnostic trajectories to address the population needs. The SARS-CoV-2 pandemic measures reinforced the problem. The current capacity in the different centers will not allow a catch up of the SARS-CoV-2related backlog. The lock-down measures negatively affected the number of diagnostic trajectories compared to previous years. In a first stage, almost all diagnostic activity was suspended. In the later phase MD activities were limited due to additional precautionary measures putting pressure on the workload. Also, the fear for contamination by clients and families reduced participation in diagnostic trajectories. Moreover, the choice to introduce an assignment stop or prioritizing specific groups (very young children) negatively impacts the waiting periods for other groups prior to SARS-CoV-2 (children in primary school). As a consequence, we expect an important societal impact in the sense that the most vulnerable children (socioeconomically and culturally) in need for diagnostics, rehabilitation and support, will be the victims of this backlog (Cloet et al., 2020). In addition, the risk of drop out of this specific target group is expected to grow.

\section{The lived experiences of children and their families}

Organizations reported that several families ended up in a crisis situation, without specification of what was meant by a "crisis". The SAR-CoV-2 measures increased the problem of drop out. While this study did not address the perspectives and experiences of the children and their families, indications are found that parents were more confronted with the dysfunction of their child when schools were closed. Stress was also induced as diagnostic assessments are formally needed before the end of the scholastic year (June) to guarantee continuation of specific support for their child with a developmental disorder. This could not be offered because of the waiting periods.

\section{And what about interorganisational collaboration?}

While the sector demands "more money to obtain more capacity", very little comments are made yet on the health services organization model of the diagnostic field: at this stage, most organizations operate in a "stand alone" way. From a theoretical point of view, health services could be organized so that people receive a continuum of services, coordinated across different levels and sites of care within and beyond the health sector and according to their needs throughout the life course. Research on interorganizational networks and 
collaborative networks offers theoretical insights which can support the reflection on a more adequate organization and coordination of health and related services (Ferlie, Montgomery, \& Reff Pedersen, 2016). It has been argued in literature that the complexity of regulating frameworks including financing, policy priorities and cultures of sectors can hamper coordination of activities and efficient and accessible care provision (E. Klijn \& Koppejan, 2016; E. Klijn, 2005). Collaboration between different organizations and sectors is the key to deal with complex problems characterized by multiple interdependent sub-components, which interact and change continuously. Theories of mandated networks learn that societal and policy goals can be reached if policy makers 'mandate' networks to implement policy and reach policy goals by assigning them with the power and responsibility to organize and deliver services (Ferlie, Fitzgerald, Mcgivern, Dopson, \& Bennett, 2011; Rodriguez, Langley, Beland, \& Denis, 2007). In order to develop such collaborative networks, one needs to understand the institutional or organizational fields (Reay \& Hinings, 2005; Scott, W. Richard;Ruef, Martin; Caronna, 2000; Scott, 1991) and institutional logics of actors (Greenwood, Díaz, Li, \& Lorente, 2010)(Thornton, Ocasio, \& Lounsbury, 2012). Interorganisational coordination and collaboration, sharing the responsibility to provide accessible care of a vulnerable population, would also be a way to use resources and capacity in a more efficient and effective way. It is striking that in this COVID-19 crisis situation causing increased accessibility problems, organizations fold back "internally" on their particular organizational practices rather than on an interorganizational approach in order to smoothen and facilitate diagnostic trajectories. The lack of interorganizational coordination and collaboration is hampered further by the fact that the different types of organizations providing multidisciplinary diagnostic assessments operate in different regulative frameworks and have different objectives. Incentives are needed to encourage a "shared responsibility" on realizing public health objectives, with better coordination of target groups, goals and activities.

The COVID-19 crisis offers sufficient arguments to further reflect on a health services model focusing on (regional) collaboration in terms of networks to improve the access to diagnostics, particularly for the most vulnerable children and their families.

\section{Methodological reflections}

To ensure that policy responses are well-informed, decision makers need rapid access to research evidence. Rapid response studies are a technique to enhance evidence informed policy making and is considered as a technique for knowledge translation (Parkhurst, 2017; Petticrew, 2003) This rapid response research collects primary data focusing on the local context performed in a very short term. A number of methodological limitations have to be considered:

First, we did not engage in a quick synthesis of available literature, mainly inspired by the fact that we are working in a particular institutional context, but also since this study connects with a more general study of the sector.

Secondly, the field work was limited to publicly recognized and subsidized providers providing MD of neurodevelopmental disorders for children as a core activity. Other types of facilities and private settings offering diagnostics (often as secondary or tertiary activity) were not included in the study. The choice to limit the study to the publicly funded organizations was made in agreement with the commissioners of the report, also motivated by the fact that the "institutional field" of private providers is quite different requiring different types of policy interventions and that the private field is not offering true MD.

Thirdly, we only collected written responses using an online survey. Questions were open ended to assemble as much qualitative information as possible on this short term. Questionnaires were sent by e-mail to the responsible directors, coordinators, or department head clinicians of the organizations. Additional in-depth interviews or focus groups would have been useful to collect detailed information about respondents' perspectives and reaction to the problem and a better understanding of the particular contexts in which they operate. We only gained insight in the "organizational" point of view of publicly funded actors providing MD; we did not provide an analysis of the internal stakeholders' perspectives (managerial, clinical, financial,...) that would offer a more detailed perspective on the impact of the policy measures.

We are aware that our data collection technique is limited. However, as it is a follow-up of a longer-term study performed shortly before, this data collection allowed to respond and support policy makers within 6 weeks. Taking into account the potential bias and limitations, the findings of this rapid response study corroborate the findings of the previous report: the lock-down measures reinforce the problem of accessibility.

\section{Conclusion}

The impact of the SARS-CoV-2 pandemic reinforced the problem of accessibility of MD for children suspected of a neurodevelopmental disorder in Flanders, Belgium. On the one hand, there is a general shortage of diagnostic capacity particularly for certain age and 
pathology groups. More importantly though, the capacity and accessibility problem needs an approach that explores how interorganizational collaboration can be strengthened. From a health services and public health model of care perspective, reflections are needed on how levels of care can be provided in a well-organized way, so that more trajectories in adequate facilities can be organized. Healthcare Policy makers should incentivize this interorganisational health services model. Network mapping and optimization should be an integral part of strategic capacity planning.

On a shorter term, accessibility problems can be tempered by providing "bridging care", helping children and families with needs to overcome "gaps" of care and support during waiting periods. On the longer term a detailed assessment of what type diagnostics and support are needed most frequently, how this can be organized in proximity of the child and its family, and which type of diagnostics can be organized on a larger geographical zone, is required.

The evolution of the accessibility of MD of neurodevelopmental disorders for children must be monitored over time and the organization of health services should guarantee optimal care trajectories for all vulnerable children.

\section{List Of Abbreviations}

MD multidisciplinary diagnostics

\section{Declarations}

\section{Ethics approval and consent to participate}

It concerns a research project addressing questions regarding organizational issues and strategies without any reference to personal data. No personal health data were collected or subject to the analysis All methods were carried out in accordance with relevant guidelines and regulations for qualitative data-analysis and reporting. As there were no experiments involved, approvement by an institutional and/or licensing committee was not applicable.

Participants were free to answer the questionnaire or not to participate. The introduction of the questionnaire clearly mentioned the purpose of the project, being a rapid response study commissioned by the Flemish authorities. Seen the design and methods of the study, an individual informed consent from all subjects was not of relevance.

\section{Consent for publication}

The Dutch report, including results and recommendations of this commissioned study, has already set free for distribution by the involved Flemish authorities. There is a consent by all partners to publish the findings in the public domain.

As the manuscript do not contain information or images that could lead to identification of a study participant, consent of publication of the participants is not applicable.

Availability of data and materials

The datasets used and/or analyzed during the current study are available from the corresponding author on reasonable request.

Competing interests

There are no competing interests.

Funding

Not applicable.

\section{Authors' contributions}

Eva Cloet is the main author, Anna Jansen reviewed the article, Mark Leys contributed to the design of the work , the interpretation of data and reviewed the article.

All authors have approved the submitted version. 
Not applicable.

\section{References}

Abdalla, M. M., Oliveira, L. G. L., Azevedo, C. E. F., \& Gonzalez, R. K. (2017). QUALITY IN QUALITATIVE ORGANIZATIONAL RESEARCH: TYPES OF TRIANGULATION AS A METHODOLOGICAL. https://doi.org/10.13058/raep.2018.v19n1.578

American Psychiatric Association. (2014). Handboek voor de Classificatie van Psychische Stoornissen (DSM 5). Nederlandse vertaling van Diagnostic and Statistical Manual of Mental Disorders, 5th edition. Amsterdam: Boom.

Belotto, M. J. (2018). Data Analysis Methods for Qualitative Research: Managing the Challenges of Coding, Interrater Reliability, and Thematic Analysis. In The Qualitative Report (Vol. 23).

Cloet, E., Kimpe, E., Van Ransbeeck, T., \& Leys, M. (2020). De toegankelijkheid van multidisciplinaire diagnostiek van ontwikkelingsstoornissen in Vlaanderen. Brussel, Belgium.

Ferlie, E., Fitzgerald, L., Mcgivern, G., Dopson, S., \& Bennett, C. (2011). Public policy networks and "wicked problems": A nascent solution? Public Administration, 89(2), 307-324. https://doi.org/10.1111/j.1467-9299.2010.01896.x

Ferlie, E., Montgomery, K., \& Reff Pedersen, A. (2016). The Oxford Handbook of Healthcare Management. Oxford, U.K.: Oxford University Press.

Greenwood, R., Díaz, A. M., Li, S. X., \& Lorente, J. C. (2010). The Multiplicity of Institutional Logics and the Heterogeneity of Organizational Responses. Organization Science, 21(2), 521-539. https://doi.org/10.1287/orsc.1090.0453

Israel, S. (2016). How social policies can improve financial accessibility of healthcare: a multi-level analysis of unmet medical need in European countries. International Journal for Equity in Health, 15(1), 41. https://doi.org/10.1186/s12939-016-0335-7

Jonsen, K., \& Jehn, K. A. (n.d.). Using triangulation to validate themes in qualitative studies.

https://doi.org/10.1108/17465640910978391

Klijn, E., \& Koppejan, J. F. (2016). Governance networks in the public sector. Oxon: Routeledge.

Klijn, Erik-hans. (2005). designing and managing networks: possibilities and limitations for network management. European Political Science, 4(3), 328-339. https://doi.org/10.1057/palgrave.eps.2210035

Maguire, M., \& Delahunt, B. (2017). Doing a thematic analysis: A practical, step-by-step guide for learning and teaching scholars. All Ireland Journal of Higher Education, 9(3). Retrieved from http://ojs.aishe.org/index.php/aishe-j/article/view/335

Majnemer, A. (1998). Benefits of early intervention for children with developmental disabilities. Seminars in Pediatric Neurology, 5(1), 62-69. https://doi.org/10.1016/S1071-9091(98)80020-X

Ozonoff, S. (2015). Editorial: Early detection of mental health and neurodevelopmental disorders: The ethical challenges of a field in its infancy. Journal of Child Psychology and Psychiatry and Allied Disciplines, 56(9), 933-935. https://doi.org/10.1111/jcpp.12452

Parkhurst, J. (2017). The politics of evidence: from evidence-based policy to the good governance of evidence Book (Published version) CC BY-NC-ND.

Penchansky, R., \& Thomas, J. W. (1981). The Concept of Access. Medical Care, 19(2), 127-140. https://doi.org/10.1097/00005650198102000-00001

Petersen, M. C., Kube, D. A., \& Palmer, F. B. (1998). Classification of developmental delays. Seminars in Pediatric Neurology, 5(1), 2-14. https://doi.org/10.1016/S1071-9091(98)80012-0

Petticrew, M. (2003). Evidence, hierarchies, and typologies: horses for courses. In J Epidemiol Community Health (Vol. 57). Retrieved from http://www.evidencenetwork.org/ 
Reay, T., \& Hinings, C. R. (Bob). (2005). The Recomposition of an Organizational Field: Health Care in Alberta. Organization Studies, 26(3), 351-384. https://doi.org/10.1177/0170840605050872

Rodriguez, C., Langley, A., Beland, F., \& Denis, J.-L. (2007). Governance, Power, and Mandated Collaboration in an Interorganizational Network. Administration \& Society, 39(2), 150-193. https://doi.org/10.1177/0095399706297212

Saurman, E. (2016). Improving access: modifying Penchansky and Thomas's Theory of Access. Journal of Health Services Research \& Policy, 21(1), 36-39. https://doi.org/10.1177/1355819615600001

Scott, W. Richard;Ruef, Martin; Caronna, C. A. (2000). Institutional Change and Healthcare Organizations: From Professional ... - W. Richard Scott, Martin Ruef, Peter J. Mendel, Carol A. Caronna - Google Boeken. Retrieved from https://books.google.be/books?

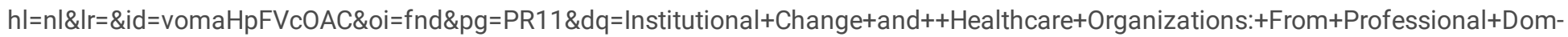
inance+to+Man-aged+Care+.+\&ots=GpfCo0CGxM\&sig=TepbYzRR3V8ocWOqa-mfrvtpqjQ\&redir_esc=y\#v=onepage\&q=Instituti

Scott, W. R. (1991). Unpacking Institutional Arguments. In P. J. Powell, Walter W.; Di Maggio (Ed.), The New Institutionalism in Organizational Analysis (pp. 164-182). Chicago: The University of Chicago Press, Ltd.

Thornton, P. H., Ocasio, W., \& Lounsbury, M. (2012). The institutional logics perspective: a new approach to culture, structure, and process. Oxford University Press. 